\title{
REVISITING THE ARGUMENT FROM ACTION GUIDANCE
}

\author{
Philip Fox
}

7 He philosophical Literature witnesses a by now fairly large debate about the degree to which normative notions like "ought" or "reason" are L perspective dependent. Roughly speaking, objectivists believe that what one ought to do depends on all the facts, whereas perspectivists believe that what one ought to do depends instead on one's epistemic perspective on the facts (and so only on facts that are epistemically available in some yet-to-be-specified sense). ${ }^{1}$ Their dispute traditionally revolves around examples like the following:

Doctor: Jill, a doctor, must decide how to treat her patient. She only has two options: prescribe pill $A$ or pill $B$. After careful research, her evidence decisively suggests that $A$ is the cure and $B$ is lethal. In fact, however, the reverse is true: $A$ is lethal and $B$ is the cure. Jill knows that the patient will die soon if she does nothing and that she has no time for further research. What ought Jill to do? ${ }^{2}$

1 For proponents of perspectivism, see, e.g., Andrić, "The Case of the Miners," "Objective Consequentialism and the Licensing Dilemma," and "Objective Consequentialism and the Rationales of 'Ought' Implies 'Can'”; Jackson, "Decision-Theoretic Consequentialism and the Nearest and Dearest Objection"; Kiesewetter, "'Ought' and the Perspective of the Agent," "How Reasons Are Sensitive to Available Evidence," and The Normativity of Rationality; Lord, "Acting for the Right Reasons, Abilities, and Obligation"; Prichard, "Duty and Ignorance of Fact"; Robertson, "Epistemic Constraints on Practical Normativity"; and Zimmermann, Living with Uncertainty and Ignorance and Moral Obligation. For proponents of objectivism, see, e.g., Bykvist, "How to Do Wrong Knowingly and Get Away with It"; Graham, "In Defense of Objectivism about Moral Obligation"; Littlejohn, "Do Reasons and Evidence Share the Same Residence?"; Moore, Ethics; and Thomson, "Imposing Risks" and Normativity.

2 This example is taken from Kiesewetter (“'Ought' and the Perspective of the Agent”), who presents it as a simplified version of a case by Jackson ("Decision-Theoretic Consequentialism and the Nearest and Dearest Objection”). Similar examples are discussed in Andrić, "Objective Consequentialism and the Licensing Dilemma"; Kiesewetter, The Normativity of Rationality; Graham, "In Defense of Objectivism about Moral Obligation”; McHugh and 
The answer is not obvious. On the one hand, one could side with the objectivist and say that Jill ought to prescribe $B$. After all, this is the only way of saving the patient's life. On the other hand, one could side with the perspectivist and say that Jill ought to prescribe $A$. After all, choosing any other option seems completely irresponsible.

What makes cases like Doctor interesting is that both positions seem to have significant intuitive appeal. Even if one is initially more attracted to one of them, it is easy to imagine how someone might have ended up on the other side. Partly for that reason, there is little ground for thinking that intuition alone will help advance the debate between objectivists and perspectivists much further. At best, appealing only to our intuitions looks like a recipe for a stalemate.

Fortunately, a less intuition-based, more theory-driven approach is available. In order to pursue such an approach, this paper draws together two separate themes from the recent literature: first, that the normative is in some sense action guiding, and second, that a discussion of perspective dependence in the practical domain benefits from a discussion of similar issues in the epistemic domain. ${ }^{3}$ The main thesis is that objectivism is incompatible with a very plausible assumption about the possibility of being correctly guided by a normative theory.

Put succinctly, my argument against objectivism is as follows:

The Argument from Action Guidance

1. It is sometimes possible for a normative theory to correctly guide action.

2. If objectivism is true, this is never possible.

3. Therefore, objectivism is false.

The central advantage of this argument is that it only makes an extremely weak assumption about the action-guiding role of normative theories. In particular, it does not assume that normative theories are always capable of guiding action, and-as I will explain in more detail below—it thereby avoids recent criticisms of guidance-based arguments against objectivism.

With the main argument on the scene, let us pause briefly for a general obser-

Way, "Objectivism and Perspectivism about the Epistemic Ought"; and Way and Whiting, "Perspectivism and the Argument from Guidance."

3 For the first theme, see, e.g., Graham, "In Defense of Objectivism about Moral Obligation"; Kiesewetter, "How Reasons Are Sensitive to Available Evidence"; Lord, "Acting for the Right Reasons, Abilities, and Obligation"; Sepielli, "Subjective Normativity and Action-Guidance"; and Way and Whiting, "Perspectivism and the Argument from Guidance." For the second theme, which has received less attention, see, e.g., McHugh and Way, "Objectivism and Perspectivism about the Epistemic Ought." 
vation about arguments of this kind. I take it that all guidance-based arguments face the same choice. First, they could employ a fairly demanding notion of action guidance, in which case it will be relatively straightforward to explain why objectivism is inconsistent with it, but also correspondingly more difficult to show that this notion does not beg the question against objectivists right away; this approach is taken by Errol Lord, and it has been criticized accordingly by Clayton Littlejohn and Jonathan Way and Daniel Whiting for its strong assumptions about the possibility of action guidance. ${ }^{4}$ Or second, guidance arguments could employ a fairly modest notion of action guidance, in which case it will be relatively straightforward to show why it does not beg the question against objectivists, but correspondingly more difficult to explain why objectivism is inconsistent with it. ${ }^{5}$ This paper takes the second approach, and so for the most part I will be concerned with defending premise 2 above.

I proceed as follows. Section 1 introduces objectivism and perspectivism as two substantive views about the perspective dependence of "ought." In section 2, after setting out two central assumptions of this paper, I develop and defend an account of what it is for a normative theory to correctly guide action. Section 3 anticipates a number of potential objections to this account. In section 4 , I use this account to explain why objectivism rules out that normative theories are ever correct guides to action. Section 5 concludes. Throughout, I aim to advance the debate over the perspective dependence of "ought" beyond merely intuitive considerations and to shed light on a notion of action guidance that should be of independent interest to normative theory.

\section{OBJECTIVISM AND PERSPECTIVISM}

I have already mentioned Doctor, a representative example that illustrates the disagreement between objectivists and perspectivists. To repeat, Jill has two pills available to treat her patient: pill $A$, which would be lethal, and pill $B$, which would cure the patient. She also has decisive but misleading evidence about which is which. What ought Jill to do?

Objectivists will say that Jill ought to prescribe $B$, because, on their view, what one ought to do depends on all the facts. This includes the fact that pre-

4 Lord, "Acting for the Right Reasons, Abilities, and Obligation"; Littlejohn, "Prichard's Question and Reasons Perspectivism"; Way and Whiting, "Perspectivism and the Argument from Guidance."

5 Kiesewetter's "misguidance argument" also seems to fall into the category of arguments that only make minimal assumptions about action guidance ("How Reasons Are Sensitive to Available Evidence"). 
scribing $B$ will actually cure the patient, which-if there is no epistemic filter that reason-giving facts must pass - we can plausibly assume to be a decisive reason to prescribe $B$. Perspectivists, however, will say that Jill ought to prescribe $A$, because, on their view, what one ought to do depends on one's epistemic perspective on the facts. Since Jill's available evidence decisively suggests that only A will cure the patient, it is this pill that she ought to prescribe according to perspectivism.

As I have indicated, there is a question about what exactly it means for a normative notion like "ought" to depend on one's epistemic perspective. ${ }^{6}$ Since my argument against objectivism does not depend on this question, I will not say much about it here. To simplify the presentation and without further argument, I will adopt Benjamin Kiesewetter's elaborate version, which has been particularly influential in the recent literature and whose central thesis is the following: ${ }^{7}$

Evidence-Relative Perspectivism: $S$ ought to $\phi$ if and only if $S$ 's available reasons decisively favor $\phi$-ing.

For our purposes, it will suffice to work with an intuitive notion of "available

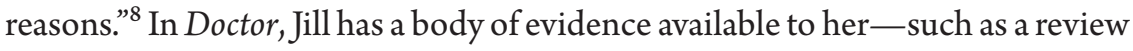
of recent articles from medical journals and the opinion of her well-respected colleagues - that gives her strong reasons in favor of prescribing $A$. Furthermore, all facts that might count against prescribing $A$, including the fact that it will kill the patient, are epistemically unavailable to her in any intuitive sense: by assumption, she does not know that these facts obtain, nor is she in a position to know or even justifiably believe them. On a perspectivist reading, any plausible normative theory will thus entail that Jill's reasons to prescribe $A$ are overall decisive and so she ought to prescribe $A$.

We have seen that objectivism and perspectivism entail conflicting verdicts about what Jill ought to do. Before I discuss the relative plausibility of these views, however, let me try to preempt (though perhaps not decisively) a suspicion that might have occurred to the reader by now: that the dispute between objectivists and perspectivists is merely verbal.

In particular, we could follow the lead of what we can call disambiguationist views, which recommend distinguishing between two different notions of

6 See, e.g., Zimmermann, Ignorance and Moral Obligation; Kiesewetter, "What Kind of Perspectivism?”

7 Kiesewetter, "'Ought' and the Perspective of the Agent," "How Reasons Are Sensitive to Available Evidence," The Normativity of Rationality, and "What Kind of Perspectivism?"

8 For further discussion, cf. Kiesewetter, "How Reasons Are Sensitive to Available Evidence" and "What Kind of Perspectivism?" 
"ought." On such a view, Jill ought objectively to prescribe $B$, but ought subjectively to prescribe $A$. With such a distinction at hand, we might then say that objectivists and perspectivists do not have a substantive disagreement. They would both be right about Jill in different senses.

Like most other parties to the debate, however, I do not think that the problem can be solved so easily. ${ }^{9}$ The reason for this lies in the nature of the deliberative "ought," which is the kind of "ought" that we are interested in here. A judgment of the form "I ought to $\phi$ " is supposed to answer the deliberative question, "What ought I to do?" in a way that concludes my deliberation and allows me to make a rational decision on the basis of my deliberation. Importantly, an "ought" judgment can do this only if it employs a univocal notion of "ought." For I might know in a given situation that I ought subjectively $_{\text {to }}$ prescribe $A$ and that I

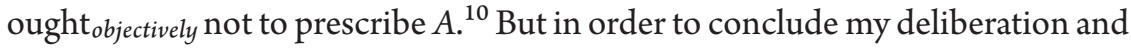
make a decision on this basis, I still need to know what I ought to do, all things considered. There is no point in disambiguating, again, between a sense in which I ought all things considered $\mathrm{subjectively}_{\text {to }}$ prescribe $A$ and a sense in which I ought

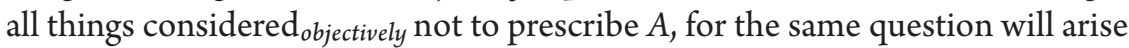
all over again. Unless there is, at some point, a univocal answer to the question of what I ought to do period, I cannot conclude my deliberation in the way that is necessary for me to make a rational decision on the basis of such deliberation. What objectivists and perspectivists have a substantive disagreement about is whether what one ought to do in the univocal deliberative sense is perspective dependent or not. ${ }^{11}$

9 People who share this assessment include, e.g., Graham, "In Defense of Objectivism about Moral Obligation"; Kiesewetter, "How Reasons Are Sensitive to Available Evidence"; Jackson, "Decision-Theoretic Consequentialism and the Nearest and Dearest Objection"; Kolodny and MacFarlane, "Ifs and Oughts"; Lord, "Acting for the Right Reasons, Abilities, and Obligation"; Piller, "Ewing's Problem"; and Way and Whiting, "Perspectivism and the Argument from Guidance."

10 For example, suppose a doctor has three pills available to her: pill $A$ cures the patient, pill $B$ significantly improves the patient's condition (without curing her completely), and pill $C$ kills the patient. The doctor knows about $B$ 's effects, but she does not know which of $A$ and $C$ cures and kills the patient, respectively. (This is the famous Jackson Case in Jackson, "Decision-Theoretic Consequentialism and the Nearest and Dearest Objection.”) In this example, the doctor might well know that she ought subjectively $_{\text {to prescribe } B \text { but that she ought }}$ objectively

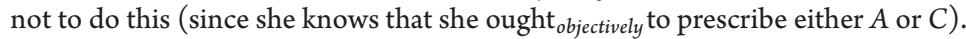

11 For a helpful, more detailed discussion of the problems with disambiguationism, see, e.g., Henning, "Normative Reasons Contextualism." There is another family of views that one could take about the perspective dependence of normative notions like "ought" or "reason," which is similar in spirit to disambiguationism but more sophisticated in its development. According to these broadly contextualist or relativist views, there is indeed a univocal notion of "ought" or "reason," but a statement containing these notions either expresses differ- 


\section{ACTION GUIDANCE}

This section has two aims. First, I set out two central assumptions of my argument, one about the possibility of action guidance and the other about the relationship between objectivism in the practical and the epistemic domains. Second, I offer a substantive but still sufficiently generic account of what it is for a normative theory to be correctly action guiding.

\subsection{Preliminaries}

Let me begin with two important assumptions. Although I will briefly explain the motivation behind each of them, I will not defend these assumptions in any detail. My aim at this point is just to lay them out as clearly as possible.

The first assumption is one that I have already mentioned: it is the first premise of the Argument from Action Guidance, which says that it is sometimes possible for an agent to be correctly guided by a normative theory. It is important to see why this is an extremely weak, and correspondingly plausible, assumption.

I will say more about what exactly it means to be correctly guided by a normative theory later. For now, let us stick to an intuitive notion of action guidance and focus on the modal status of the assumption. Intuitively, being correctly guided by a normative theory amounts to something like this: an agent does what a normative theory tells her to do because she correctly recognizes that this is what the theory tells her to do. (Note that this notion of correct guidance is an essentially relative or procedural one: if your $\phi$-ing is correctly guided by some theory, this does not mean that your $\phi$-ing is correct, only that it is correct according to that theory, or that you have correctly applied the theory in arriving at this verdict.)

Especially if you happen to be a professional philosopher, it is not unlikely that you are familiar with this phenomenon. It is not unlikely, that is, that at some point in your life, you have asked yourself which course of action a particular normative theory would recommend in your circumstances, and perhaps, given that you also believed the theory in question, you actually followed that

ent propositions in different contexts or expresses the same proposition whose truth value varies according to context (for an expressivist variation on this theme, see, e.g., Björnsson and Finlay, "Metaethical Contextualism Defended"; Henning, "Normative Reasons Contextualism"; Kolodny and MacFarlane, "Ifs and Oughts"; Pittard and Worsnip, "Metanormative Contextualism and Normative Uncertainty"; and Schroeder, "Getting Perspective on Objective Reasons"). However, a detailed discussion of such views is well beyond the scope of this paper. My aim is only to raise a new challenge for objectivism, which is one that perspectivism turns out to be able to meet. But I want to remain neutral about the merits of perspectivism vis-à-vis these other possible views. 
recommendation. If this is what you have done, and you were right about what the theory recommended, then you have been correctly guided by a normative theory in the sense that is relevant for my argument (perhaps setting aside contrived cases, e.g., those involving deviant causal chains).

More importantly, even if you have never actually been guided by a normative theory in this sense, this does not make it any less plausible that one could have been guided in this sense. All that needs to be the case for that claim to be true is for it to be possible for someone, under some circumstances, to correctly apply a normative theory in practice. This is all that the first premise requires and it is, as I have said, very plausible.

This is in large part because the modal status of the premise is so weak. For all that it says, it might be the case that whenever an agent faces a decision under ignorance, it will no longer be possible for her to be correctly guided by a normative theory. This is consistent with my assumption about guidance, as long as there remain some cases where an agent is correctly guided by a normative theory. In general, the premise does not require that, in any possible situation, there is at least one normative theory that could correctly guide the agent, let alone that there is a single normative theory that could always do that. These are the sorts of stronger guidance assumptions that are likely to beg the question against objectivists. Since my argument makes a much weaker assumption, it cannot be rejected on these grounds.

In fact, some objectivists, such as Peter Graham, explicitly embrace the idea that normative theories can correctly guide action. ${ }^{12}$ Graham even accepts this possibility in cases of ignorance, and he explains in detail how a normative theory could correctly guide a morally conscientious agent in such cases, even if objectivism is true. Similarly, Way and Whiting argue on behalf of objectivism that this view is perfectly consistent with the idea that normative theories sometimes provide correct action guidance. ${ }^{13}$ This is further evidence that the weak guidance premise is independently plausible and does not beg the question against objectivists. I will hence assume it in what follows. ${ }^{14}$

12 Graham, "In Defense of Objectivism about Moral Obligation."

13 Way and Whiting, "Perspectivism and the Argument from Guidance."

14 Another consideration is that one of the main motivations for objectivism-that it is the best account of our practice of advice (see, e.g., Graham, "In Defense of Objectivism about Moral Obligation") - fits quite badly with denying that the normative is possibly action guiding. This is because it is hard to see why advice would be an important normative phenomenon if it were not at least sometimes possible for normative claims to correctly guide action. Why would people ask for advice if they did not think that responses like "You ought to $\phi$ " could correctly guide action, and why would people respond to a request for advice if they did not think that their advice could correctly guide others? The fact that we often seek 
The second assumption that I will make is that the truth of objectivism about the practical "ought" entails the truth of objectivism about the epistemic "ought." 15 This assumption is motivated on several grounds. First, whatever substantive differences between the practical and the epistemic "ought" there might be, they still seem to be instances of the same distinctive notion of all-things-considered normative assessment. Assuming that this general notion of "ought" does not behave radically differently in the two domains should thus be the default position, unless there is some positive reason for denying it. But it is far from obvious what this positive reason could be.

Second, we must keep in mind that some of the best arguments for practical objectivism are based on considerations about the practice of advice. According to one such argument, the fact that true advice about what someone ought to do can be based on the facts rather than the advisee's evidence suggests that what the advisee ought to do must itself depend on the facts rather than her evidence. ${ }^{16}$ But since it seems that true advice about what someone ought to believe can similarly be based on the facts rather than the advisee's evidence, the very same kind of argument would support epistemic objectivism. One of the central arguments in favor of practical objectivism thus generates an internal pressure to accept epistemic objectivism as well.

Third, the combination of practical objectivism and epistemic perspectivism yields conflicts with the plausible and widely acknowledged claim that it is irrational to believe that one ought to $\phi$ without intending to $\phi \cdot{ }^{17}$ If objectivism were true only in the practical domain, then in cases like Doctor it would both be true that Jill ought to believe that she ought to prescribe pill $A$ (since this is, given her evidence, most likely to be the cure) and that she ought not to intend to prescribe pill $A$ (since, we can stipulate, this would prevent her from prescrib-

and give advice, a fact that objectivists regularly emphasize, suggests that we do accept that normative claims, and so the normative theories constituted by them, can correctly guide action.

15 This assumption is widely shared in the literature. It is implicit in Gibbons (The Norm of Belief, 1-17), who takes the same considerations that motivate practical objectivism to motivate epistemic objectivism as well. Thomson thinks that objectivism has to be true in both the practical and epistemic domains (Normativity, chs. 11 and 12). The assumption that both domains ought to be treated analogously is also important in McHugh and Way, "Objectivism and Perspectivism about the Epistemic Ought," 139-40; and Littlejohn, Justification and the Truth-Connection and "The Unity of Reason."

16 Cf. Graham, "In Defense of Objectivism about Moral Obligation," 91.

Cf. Scanlon, What We Owe to Each Other, secs. 2.3, 2.4; Broome, Rationality through Reasoning, sec. 9.5; Kolodny, “How Does Coherence Matter?”; Kiesewetter, The Normativity of Rationality; Way, "The Symmetry of Rational Requirements"; Lord, "The Real Symmetry Problem(s) for Wide-Scope Accounts of Rationality." 
ing pill $B$, which is what she ought to do according to objectivism). This means, however, that if Jill conforms to both "oughts," she will necessarily be irrational. But it is implausible that in cases like Doctor, and all other cases where people have misleading evidence about what they ought to do, conforming to all the "oughts" to which one is subject is a way of ensuring one's own irrationality. ${ }^{18}$ The fact that a "hybrid" view about the perspective-dependence of "ought" entails this result is a strong reason to reject it.

\subsection{A Generic Account of Action Guidance}

With the two guiding assumptions of my argument on the table, let me now turn to the question of what exactly it means for a normative theory to correctly guide action. I will state my proposed analysis before I discuss each of its specific conditions:

Action Guidance: A normative theory $T$ correctly guides an agent $S$ toward $\phi$-ing if and only if

(A) $S \phi$-s on the basis of correct practical reasoning from $T$ toward $\phi$-ing, with A being satisfied only if

(B1) for some $R$ that is a decisive reason to $\phi$ according to $T, S$ believes that $R$ is a decisive reason to $\phi$, and

(B2) $S$ believes that $R$ is a decisive reason to $\phi$ for the reason that $E$, with $E$ being the right reason to believe this according to $T$.

In this analysis, $R$ is any practical reason, or set of practical reasons, that decisively favors $\phi$-ing according to some theory T. $E$ is the right reason, relative to that theory, to believe that $R$ is a decisive (practical) reason to $\phi$. (The qualifications are important: the requirement is not that $R$ and $E$ really are reasons for acting and believing, only that $T$ says so. I will come back to this issue soon.)

Turning now to the specific conditions asserted by the account, let us first ask what justifies A. The main idea is that a reasonable account of action guidance must explain the difference between being guided by a theory and merely acting in conformance with it. Consider the following case:

Utilitarian Demon: Since Jim believes in utilitarianism, he believes that he ought to donate a significant portion of his wealth to an efficient charity. But since he is akratic, he cannot get himself to donate. Unbeknownst

See Littlejohn, Justification and the Truth-Connection, 235, for essentially the same argument. Note that the argument does not assume that epistemic and practical "oughts" agglomerate (i.e., that " $S$ ought to believe $X$ " and " $S$ ought to do $Y$ " entails " $S$ ought to believe $X$ and do $Y$ "). It only assumes that, if you conform to each individual "ought" that applies to you, you will end up with an irrational combination of attitudes. 
to him, there is a demon who enjoys making akratic utilitarians perform what utilitarianism requires. The demon tinkers with Jim's brain and, consequently, Jim intentionally donates a significant portion of his wealth to an efficient charity.

Let us assume that Jim acts in accordance with utilitarianism, because utilitarianism really requires what Jim (and the demon) thinks it requires. Still, Jim is not correctly guided by utilitarianism. This is so although Jim believes in utilitarianism and intentionally does what utilitarianism requires, and there is a clear connection between his belief and his action.

However, the connection is of the wrong kind. Although Jim's doing what utilitarianism requires is causally connected to his belief, the move from belief to action is not guided by utilitarianism. For an agent to be correctly guided by a theory, a mere causal connection is not enough. Instead, I suggest, the connection must be one of correct practical reasoning from that theory toward the action required by it. In cases like Utilitarian Demon, the agent does not act on the basis of correct practical reasoning, and so is not correctly guided by the normative theory in question. This is why we should include A as a necessary condition for correct action guidance.

Condition A raises the following question: What makes practical reasoning correct? Obviously, I cannot provide a substantive answer here. For our purposes, it will be enough to rely on a formal answer: correct practical reasoning just is reasoning that conforms to the correct standards of practical reasoning, whatever they are. In this context, what is more important than the substance of these principles is what notion of correctness is relevant here.

Again, this is a form of procedural correctness. Roughly speaking, practical reasoning is correct in a procedural sense if it transforms correct inputs into correct outputs. The idea is not that if correct reasoning issues in a deliberative conclusion of the form "I ought to $\phi$ " it will be true that I ought to $\phi$. Rather, the point is that, if the premises of the reasoning are true and one reasons correctly from this basis, one will be guaranteed to arrive at a true deliberative conclusion. For example, if one engages in (procedurally) correct reasoning from Kantian premises, it will be guaranteed that, if these Kantian premises are true, so are the deliberative conclusions arrived at in such reasoning.

To sum up, being correctly guided by some normative theory $T$ requires that the transition from believing the theory toward action is mediated by correct practical reasoning, in a procedural sense of "correct." But what exactly does this involve? In order to provide a (partial) answer to this question, let me now turn to conditions $\mathrm{B} 1$ and $\mathrm{B} 2$, which I take to be necessary conditions for it to be true 
that someone acts on the basis of correct practical reasoning from a given normative theory.

According to $\mathrm{B} 1$, this is the case only if the agent believes $R$ to be a decisive reason to $\phi$, for some practical reason, or set of practical reasons, $R$, that decisively favors $\phi$-ing according to the normative theory in question. Why is this a necessary condition for correct action guidance?

The motivation is a broadly Kantian one (although it is not just Kantians who will find the underlying picture attractive). As Alison Hills expresses the thought in a related discussion of moral worth and what it is to act for moral reasons:

This "Kantian" theory says that to act for moral reasons requires that when you act, you are aware of the moral reasons in favour of your action, you are aware of their normative force (e.g. that the action is required, permitted, or favoured by them), and you decide to act and put that decision into action on the basis of your awareness of that force, responding appropriately, that is, rationally to it. ${ }^{19}$

According to the Kantian theory, acting for a reason requires one's awareness of these reasons as reasons. If we apply this thought to the question of what it is to be correctly guided by a normative theory, we should similarly say that it requires one's awareness (as reasons) of those normative reasons that the theory identifies as normative reasons.

To see how plausible B1 is, we can also consider what it would mean to deny it. For suppose that, according to $T$, only $R$ is a decisive reason to $\phi$, but that the agent $\phi$-s without taking $R$ to be a decisive reason to $\phi$. Whatever her $\phi$-ing is based on, this will not be something that the theory acknowledges to require $\phi$-ing. If the agent $\phi$-s in such a case, then she either $\phi$-s for no reason at all, or she $\phi$-s for some other reason that does not decisively favor $\phi$-ing according to $T$. In neither case is the agent appropriately described as $\phi$-ing on the basis of correct reasoning from $T$, a theory that says that only $R$ requires $\phi$-ing. The same is true if according to $T$ there are multiple decisive reasons for $\phi$-ing, but the agent does not take any of them to require $\phi$-ing. Therefore, we should incorporate $\mathrm{B} 1$ as a necessary condition into our account of correct action guidance.

According to $\mathrm{B} 2, S \phi$-s on the basis of correct practical reasoning from $T$ toward $\phi$-ing only if $S$ believes for the right reason $E$ that $R$ decisively favors $\phi$-ing (where, again, what makes a reason the "right" reason to believe something is

19 Hills, "What Does It Take to Act for Moral Reasons?" 247, emphasis added. Hills herself later rejects this "rational guidance" account, because she thinks that it is overly intellectualized. In section 2.3, I explain why my account of action guidance does not fall prey to this objection. 
determined by the theory in question). In contrast to $R$, which is a reason for action (relative to $T$ ), $E$ is a reason for belief (relative to $T$ ). Again, it is important to stress this last qualification: $E$ may not really be a reason to believe that $R$ decisively favors $\phi$-ing. All that is required by В 2 is that $E$ is what $T$ claims to be the right reason to believe this.

To see why this is necessary, suppose that the correct analysis of action guidance did not include B2, and consider the following example. You borrow money from your friend, promising to pay it back in due time. After a while, it occurs to you that keeping the money would actually be quite a good bargain. So you ask yourself: “Ought I really to pay it back?” When you remember your promise, you wonder whether that is not a good reason to return the money. Now, there are a variety of reasons for which you could believe that having promised something is a decisive reason to do it. You might think that your promise generates a decisive reason because breaking the promise decreases overall utility, or because this is prohibited by God's commands, or because it violates a particular code of honor, or because it is ruled out by the categorical imperative. And which of these thoughts you think must determine whether you can be correctly described as being guided by this or that particular normative theory.

Suppose you think that having promised to return the money is a decisive reason to do it because God commands that promises be kept. Then your returning the money, if that is what you end up doing, is not correctly guided by Kantianism, even if Kantianism also says that having promised to return the money is a decisive reason to do it. Although Kantianism (let us suppose) says that your promise generates a decisive reason, and you believe that your promise generates a decisive reason, you do not believe this because you take promise breaking to be ruled out by the categorical imperative, or because of some other recognizably Kantian explanation. You believe that your promise generates reasons because God has commanded that promises be kept. And so while your reasoning might be correct by a divine command theory standard, it is not correct by a Kantian standard.

Therefore, being guided by Kantianism does not just require an agent to believe that her promise decisively favors performing the promised action. It also requires that she believes this for the reason that explains, according to Kantianism, why her promise generates a decisive reason. This is why we need B2 on top of B1.

\section{OBJECTIONS}

Since my account of correct action guidance is a central element in the argument 
to come, it will be worthwhile to address a number of possible objections to it. In particular, I want to anticipate certain worries about B1 and B2, two conditions that carry much weight in the following argument. ${ }^{20}$

\subsection{Is the Account Overly Intellectualized?}

The first objection presses the worry that B1 yields an implausibly intellectualized account of action guidance. Are there not ways of being guided by a normative theory, one might ask, that do not require the agent to have the concept of a normative reason, let alone explicit beliefs about such things?

Hills discusses a similar objection to the Kantian account of acting for moral reasons mentioned above. In her view, it is sometimes perfectly felicitous to describe an agent as having acted for the right moral reasons, even if she was not aware of what these reasons were and hence did not believe them to favor the action. For example, before the concept of sexual harassment became widely known, a woman might have quit her job for the right moral reason that she was harassed, even if she did not believe that she was harassed or that being harassed is a moral reason to quit one's job. ${ }^{21}$ Similarly, one might think that agents could be guided by a normative theory "implicitly" or "subconsciously," without an explicit awareness of how the considerations that are reasons according to the theory in question favor a certain action.

In response, I want to point out that nothing in my argument commits me to denying this. For all that I say, there might well be such a thing as implicit or subconscious guidance by a theory, of which the above account is not the correct one. Still, even if that is the case, there surely is such a thing as being explicitly guided by a normative theory, which does involve practical reasoning and normative beliefs. It is this phenomenon that I seek to give an account of and that plays a role in the subsequent argument. It is problematic enough if objectivism entails that explicit action guidance in this sense is impossible, for surely it is possible to sometimes act on the basis of explicit guidance by a normative theory. For this reason, the charge of being overly intellectualized does not undermine my account of action guidance, even if it succeeds as an objection against parallel accounts of acting for the right reasons.

\subsection{Normative Theories with Too Little Explanatory Structure}

The second objection claims that $\mathrm{B} 2$ is not a necessary condition for correct action guidance. In some cases, it seems that an agent is correctly guided by a nor-

20 I owe the following objections, including the purported counterexamples in sections 3.2 and 3.3, to two anonymous referees. 
mative theory, although there is no reason $E$ for which she could rightly believe (relative to that theory) some other reason $R$ to decisively favor $\phi$-ing. For example, consider a normative theory that says both that promises generate reasons and that nothing explains why this is so. In that case, there seems to be no $E$ for which one could rightly believe (relative to that theory) that promises generate reasons. It would then follow from my account that one could not be correctly guided by that theory, which might seem like the wrong result.

In response, note first that, in my proposed analysis, $R$ is not just any reason, but a decisive one. So the theory we are imagining says, not just that nothing explains why promises generate reasons, but also why, in a given situation, the promissory reasons are decisive. It is not clear to me that this is properly called a "theory." If you think that it is simply, inexplicably true that you ought to keep your promise in a given situation, then perhaps the most plausible thing to say is that there is nothing that you have a theory about. (In fact, the envisaged view sounds reminiscent of W.D. Ross's moral pluralism, which is notoriously criticized for being insufficiently action guiding, precisely because it lacks theoretical structure. $)^{22}$

But even if we grant for the sake of the argument that this is a genuine normative theory, we can still account for this complication by being liberal about what can count as $E$ : the right reason to believe that promises generate decisive reasons, relative to different theories, might be either a substantive reason, e.g., that breaking promises violates the categorical imperative, or alternatively something like the brute fact that promises simply do create decisive reasons. Unless one believes that promises simply do create decisive reasons, the analysis then predicts - correctly, in my view - that one is not correctly guided by this sort of theory. ${ }^{23}$

\subsection{Guidance De Re and De Dicto}

Let me now turn to the final objection, which puts pressure on $\mathrm{B} 1$ by appealing

Ross, The Right and the Good. Note that I am not endorsing this as an objection to Rossian pluralism. I just mention it to support the claim that many people seem to think that Rossian pluralism has too little structure to count as a genuine normative theory, whether or not that is a reason to reject it.

23 One must also keep in mind that B2 is merely a necessary condition. Several different theories might all claim that promises simply do create decisive reasons. If you keep a promise on the basis of such a thought, conditions B1 and B2 are silent on which of these theories has correctly guided you. Since they are not sufficient conditions, my account does not implausibly entail that, whenever you keep your promise on the basis of such a thought, you automatically count as being guided by any normative theory according to which the normative force of promises has no further explanation. 
to cases where agents seem to be correctly guided by disjunctive considerations. To illustrate, consider the following example:

Disjunctive: Yesterday, Jane borrowed Jack's pen. Today, she asks herself whether she ought to return it. Jane accepts normative theory $D$ according to which one ought to $\phi$ if and only if either (i) $\phi$-ing keeps a promise or (ii) $\phi$-ing maximizes overall utility. She also believes that returning Jack's pen either keeps a promise or maximizes overall utility (but not both), and decides to return the pen on the basis of accepting this disjunction. As a matter of fact, Jane has indeed promised to return Jack's pen, but returning it does not maximize overall utility. ${ }^{24}$

Could Jane count as having been correctly guided by $D$ ? Intuitively, yes. But according to Action Guidance, the answer seems to be no. This is because, according to $\mathrm{B} 1$, an agent is correctly guided by a normative theory $T$ only if she correctly believes, for some $R$ that is a decisive reason according to $T$, that it decisively favors her action. But in Disjunctive, it seems that there is no such $R$.

To see why, consider three possible candidates: the true proposition (a) that Jane has promised to return the pen; the false proposition (b) that returning the pen maximizes overall utility; the true proposition (c) that returning the pen either keeps a promise or maximizes overall utility.

It cannot be (a) or (b), because Jane believes neither of them. The only remaining candidate is thus (c). The problem is that, as the case is described, the disjunction (c) is not a reason according to $D$ (whatever Jane believes about it). ${ }^{25}$ According to $D$, only two considerations could be a reason for returning the pen: (i) that doing so keeps a promise, or (ii) that it maximizes overall utility (but not their disjunction). And still, it both seems that Jane could be properly guided by the disjunction and that there is a natural way of describing the resulting action as being correctly guided by $D$. If that is right, $\mathrm{B} 1$ cannot be a necessary condition for correct action guidance.

What is the right way to reply to this objection? I think a careful description of the case points toward a solution. Why is it intuitively plausible in the first place to say that Jane has been correctly guided by $D$ ? It is a crucial element of the case that D's criterion of rightness is a disjunctive one. It is for this very

24 Admittedly, this is a contrived case. Perhaps the easiest way to imagine it is by stipulating that Jane loses her memory after making the promise and that a reliable informant later tells her that returning the pen either keeps her promise or maximizes overall utility (but not both).

25 We can leave it open whether $D$ is right to exclude disjunctive considerations from being reasons. What matters is only that it does. The mere fact that a normative theory is mistaken does not entail that one cannot be correctly guided by it, in the procedural sense of "correct." 
reason that Jane does not need to know which of the specific Rs that would be decisive reasons according to $D$ actually obtains. She is still in a position to know that something requires $\phi$-ing according to $D$, even if she cannot know which fact makes this the case. And that puts her in a position to correctly apply $D$ as a guide to action.

What does this mean for the status of Action Guidance? I think that reflection on the example shows that there are in fact two interestingly different ways in which в1 can be satisfied. On the first reading, the agent must correctly believe, for some specific consideration $R$, that it is a decisive reason according to $T$, in the sense of being able to actually say what that consideration is (e.g., that the action keeps a promise). Call this the de re reading. On the second reading, the agent must correctly believe that some consideration $R$ is a decisive reason according to $T$, but she need not be able to specify what exactly this consideration is. In other words, she only needs to correctly believe that some consideration, whatever it is, is a decisive reason according to $T$. Call this the de dicto reading.

Once we make this distinction, we can see that there are two different ways for $\mathrm{B} 1$ to be true. In ordinary cases, the agent will be guided in the de re sense by her correct beliefs about which specific considerations are decisive reasons according to the theory in question. However, in cases like Disjunctive where guidance de re is unavailable, the agent can still be guided in the de dicto sense by her correct belief that some consideration is a decisive reason according to that theory, even if she is unable to specify which it is. But since correct guidance de dicto is correct guidance all the same, B1 properly understood actually vindicates the intuitive verdict that Jane could be correctly guided by $D .{ }^{26}$ We must only keep in mind that it also has a de dicto reading.

This completes my discussion of potential objections to Action Guidance. In

26 Perhaps you reject the claim that guidance de dicto is a genuine case of correct guidance, partly on the basis of cases like the following: Jack accepts Kantianism; a reliable informant correctly tells him that (but not why) Kantianism requires $\phi$-ing; Jack $\phi$-s on the basis of such testimony. Has Jack been correctly guided by Kantianism? I myself do not have a very clear intuition about this. I am inclined to say that he has (albeit perhaps not to the same degree as in the "pure" cases), since there is after all a recognizable sense in which his $\phi$-ing is essentially due to his acceptance of Kantianism and a correct belief about what it requires. But the point is this: if you think that an agent has to know which specific consideration decisively favors $\phi$-ing according to a theory in order to count as being correctly guided by it, then cases like Disjunctive should not strike you as convincing counterexamples to begin with. If, that is, only guidance de re is correct guidance, then Jane's clearly is not a case of someone being correctly guided by $D$, since her returning the pen is not guided by an appreciation of a specific consideration that favors this action according to $D$. On this view, there is no problem for Action Guidance in the first place, as long as one insists that only the de re reading of $\mathrm{B} 1$ is legitimate. 
the next section, I will use this account to develop my main argument against objectivism.

\section{WHY OBJECTIVISM RULES OUT ACTION GUIDANCE}

To repeat, being correctly guided by a normative theory is a matter of moving from that theory toward an action required by the theory via correct practical reasoning. This reasoning is correct only if the agent correctly believes that $R$ decisively favors her action, for some $R$ that does this according to the theory, and she believes this for the reason $E$, which is the right reason to believe this according to the theory. This section argues on the basis of this account that, if objectivism is true, it is impossible for a normative theory to correctly guide action in this sense.

\subsection{The Infection Argument}

Let me start with the main idea: objectivists about practical normativity are committed to objectivism about epistemic normativity. But since epistemic objectivism makes it impossible to believe normative facts for the right reason, it thereby infects the action-guiding capacity of normative theories. Here is a summary of the argument:

\section{The Infection Argument}

1. Epistemic objectivism implies that it is impossible to believe normative propositions for the right reason.

2. One is correctly guided by a normative theory only if it is possible to believe normative propositions for the right reason.

3. Therefore, epistemic objectivism implies that one is never correctly guided by a normative theory (from 1 and 2 ).

4. Furthermore, practical objectivism implies epistemic objectivism.

5. Therefore, practical objectivism implies that one is never correctly guided by a normative theory (from 3 and 4 ).

I have already defended 2 above. Even if someone believes that $R$ decisively favors $\phi$-ing, she is not correctly guided by that theory if she does not believe this for the reason that explains, according to the theory in question, why $R$ decisively favors $\phi$-ing. Furthermore, 4 is among the guiding assumptions that I have briefly defended above. Hence, only 1 , which says that epistemic objectivism is inconsistent with believing normative propositions for the right reason, needs further defense. The rest of this section embarks on this task.

What exactly is epistemic objectivism? Roughly speaking, it is the view that 
what one ought to believe depends on all the facts, rather than on one's epistemic perspective. ${ }^{27}$ It contrasts with epistemic perspectivism, which says that what one ought to believe depends only on epistemically available facts, such as the evidence that is available to the agent during doxastic deliberation.

In order to characterize epistemic objectivism more precisely, we should follow suggestions by Daniel Whiting, Conor McHugh, and Jonathan Way and deny that, according to epistemic objectivism, $S$ ought to believe $p$ if and only if $p$ is true. ${ }^{28}$ We should not, that is, ascribe to epistemic objectivists the view that one ought to believe just any old truth, no matter how trivial or uninteresting. On a more careful characterization, epistemic objectivism claims that it is permissible to believe $p$ if and only if $p$ is true. ${ }^{29}$ This gives epistemic objectivists all that they should want: it is not the case that one ought to believe just any old truth, but what it is permissible to believe is still fully dependent on all the facts rather than one's epistemic perspective.

The remainder of the section proceeds in three steps. First, I argue that if one accepts epistemic objectivism one should accept that $p$ is a reason to believe $p$. Second, I argue that epistemic objectivists who accept that $p$ is a reason to believe $p$ should also accept that only $p$-as opposed to independent evidence bearing on whether $p$-is a reason to believe $p$. Third, I explain why, if only $p$ is a reason to believe $p$, for some normative proposition $p$, it is impossible to believe $p$ for the right reason.

\subsection{If Epistemic Objectivism Is True, Then $\mathrm{p}$ Is a Reason to Believe $\mathrm{p}$}

Let us start with the first commitment of epistemic objectivism. Why does epistemic objectivism entail that $p$ is a reason to believe $p ?^{30}$ First, recall that, accord-

27 For versions of epistemic objectivism, see, e.g., Boghossian, “Is Meaning Normative?”; Gibbard, "Truth and Correct Belief"; Littlejohn, Justification and the Truth-Connection; Schroeder, "Knowledge Is Belief for Sufficient (Objective and Subjective) Reasons"; Shah, "How Truth Governs Belief"; Shah and Velleman, "Doxastic Deliberation"; Wedgwood, "The Aim of Belief"; and Whiting, "Should I Believe the Truth?"

Whiting, "Should I Believe the Truth?”; McHugh and Way, "Objectivism and Perspectivism about the Epistemic Ought."

Some people might find it unnatural to speak of what it is "permissible" to believe, as opposed to which beliefs are justified or warranted. I myself do not find this expression problematic, as long as one keeps in mind that responding to what it is permissible to believe need not be thought of in the same way as responding to what it is permissible to do. (Typically, one does not first register a permission to believe $p$ and then go on to believe it, in the same way in which one might first register a permission to do something and then go on to do it.) Furthermore, speaking of epistemic permissions is common practice in the debate that I am engaging in here, and I will rely on it in what follows.

This commitment (or something close to it) seems to be explicit in McHugh and Way, "Ob- 
ing to epistemic objectivism, the normative status of believing $p$ depends on $p$ 's truth. But if that is so, what could speak more clearly in favor of believing $p$ than the fact that $p$ is true? If the agent's epistemic perspective does not affect the permissibility of a belief, and what it is permissible to believe depends instead on all the facts, then why exclude the fact that $p$ ?

Let us say that if the conditional probability of $q$ given $p$ is greater than the unconditional probability of $q$, then $p$ is a probabilifier with respect to $q$. Now suppose epistemic objectivists deny that $p$ is a reason to believe $p$. On this view, if there are any reasons to believe $p$ at all, then probabilifiers $q, r, s$, etc. are reasons to believe $p$, while $p$ is not a reason, although $p$ is a probabilifier just like $q, r$, $s$, etc. (It does not fail to be a probabilifier just because it raises $p$ 's probability to 1 rather than, say, o.9.) Indeed, since it maximally increases the probability of $p$, it is, if anything, the paradigm case of a probabilifier with respect to $p$, in which case $p$ seems to be a reason to believe $p$ just like the other probabilifiers. Therefore, it seems that if objectivism is true, the fact that the candidate in fact won the election is a reason to believe that she won the election. ${ }^{31}$

Of course, perspectivists have grounds for denying that $p$ is a reason to believe $p$. They believe that reasons must be epistemically available facts that one can rationally appeal to in deliberation. But cases of doxastic deliberation about $p$ are precisely cases where the agent is about to decide whether $p$ is true, which explains why at that time $p$ is not among the available facts that one can rationally appeal to. Hence it is not a reason as far as perspectivism is concerned. But since objectivists deny that reasons must be epistemically available in such a sense, they cannot reject that $p$ is a reason on these grounds. Unless one follows perspectivism to accept such restrictions on what can count as a reason, it just

jectivism and Perspectivism about the Epistemic Ought," 133, and Schroeder, "Knowledge Is Belief for Sufficient (Objective and Subjective) Reasons," sec. 2, who assume on behalf of objectivism that $p$ 's falsity is a reason not to believe $p$-if we make this assumption, it also seems reasonable to accept that $p$ 's truth is a reason to believe $p$. Littlejohn, himself an objectivist, seems to accept this for normative facts, which we are concerned with here: "Suppose that it is a fact that A ought to $\phi$. If so, this fact should be part of the evidence there is. If it is evidence for anything, it should be evidence for itself" " Do Reasons and Evidence Share the Same Residence?" 4). Presumably, he would then say that, since evidence for $p$ is a reason to believe $p, p$ is a reason to believe $p$.

Cf. Matt Weiner: "What we should believe with all the facts at our disposal and unlimited mental power to process them ... are all and only the true propositions. If we could help ourselves to all the facts, then we could help ourselves to the facts about whether any given proposition is true, and that is enough to determine that we should believe it" ("The Spectra of Epistemic Norms," 205-6). As Weiner says, if one were aware of $p$ 's truth, this would be "enough to determine" that one should believe $p$. In such a case, $p$ 's truth would be a (decisive) reason to believe $p$. 
seems ad hoc to exclude $p$ from the class of probabilifiers that are reasons to believe $p$.

Second, denying that $p$ is a reason to believe $p$ makes the intuitive motivation for epistemic objectivism look quite sparse. Objectivism would then say that probabilifiers are reasons to believe some proposition, as long as they are different from that very proposition. Since probabilifiers are sometimes non-veridical, probabilifying false propositions, there will be reasons to believe false propositions even on objectivism so understood. ${ }^{32}$ But if objectivists already allow that there can be reasons to believe false propositions, it just becomes odd to maintain that these reasons are necessarily overridden, for any proposition and under all circumstances. If these are reasons with genuine normative force, then would not it have to be possible, at least under certain circumstances, for them to permit a belief that is false but extremely well supported by independent evidence?

In general, it does not look like an intuitively attractive combination of views to think both that independent evidence for some falsehood $p$ can provide genuine reasons to believe $p$ and that it is necessarily impermissible to believe a falsehood, even when the independent evidence in support of it is incredibly strong. Objectivism would seem much better motivated if it claimed that, since believing as one ought to is a matter of believing truly (rather than having beliefs that are likely to be true), only the fact that $p$ is true (rather than that it is likely to be true) is a reason to believe $p$. (We will see shortly why it is "only" $p$ 's truth.)

Third, it is very plausible to assume that reasons are considerations that can make something permissible. In the practical case, for example, reasons to spend time with my friends tonight rather than work an extra shift in the office are considerations that, if sufficiently strong, can make it permissible to spend time with my friends tonight. Return now to the epistemic case: if $p$ itself were not a reason to believe $p$, it turns out that this natural view is mistaken. If epistemic objectivism is true, then $p$ 's truth alone makes it permissible to believe $p$. But it is not, on the present suggestion, a reason to believe $p$. At the same time, the considerations that are supposed to be reasons to believe $p$-independent evidence for $p$-are not the kinds of considerations that make believing $p$ permissible. Either $p$ is true, in which case it is permissible to believe $p$ whatever the evidence says, or $p$ is false, in which case it is impermissible to believe $p$ whatever the evidence says. Whatever independent evidence there is, it does not make any difference to the permissibility of a belief. Hence, if $p$ were not a reason to believe $p$, this would implausibly entail that reasons for belief are not the kinds of consideration

32 Technically, it could be that only veridical probabilifiers are reasons. But that view looks even more gerrymandered and without any intuitive motivation. I disregard it here. 
that can make belief permissible. For these reasons, I conclude that, if epistemic objectivism is true, then $p$ is a reason to believe $p$.

\subsection{If Epistemic Objectivism Is True, Then Only $\mathrm{p}$ Is a Reason to Believe $\mathrm{p}$}

Consider now the second step and ask whether objectivists could say that both $p$ 's truth and independent evidence bearing on whether $p$ are reasons to believe $p$. The problem is that this view conflicts with at least two plausible constraints on reasons.

The first constraint is:

Impact Constraint: If $R$ is a reason to $\phi$, then $R$ could make a difference, or contribute, to its being the case that one ought to $\phi$.

I take it that there is an intuitive sense in which reasons are the kinds of things that make a difference to "ought" facts. Whenever we weigh up reasons for and against something, we do so precisely because we thereby try to track those considerations that help to make it the case that we ought (or ought not) to respond in a certain way. In the practical case, for example, it is very natural to think that something like my having promised to $\phi$ makes a difference, or contributes, to it being the case that I ought to $\phi$ (even if all things considered I ought not to $\phi$ ).

However, as I have already suggested, independent evidence fails to be difference making in this sense. If $p$ is true, it is ipso facto permissible to believe $p$ whatever the independent evidence says; if $p$ is false, it is ipso facto impermissible. If epistemic objectivism is true, independent evidence bearing on $p$, in contrast to $p$ 's truth itself, does not have any influence on the permissibility of a belief.

Indeed, one can say more. A useful, maximally weak heuristic for finding out whether a consideration of a certain kind makes the right kind of difference in order for it to be a reason seems to be this: suppose first that $\phi$-ing is impermissible. Then ask yourself whether it is at least conceivable that, by adding more and more considerations of that kind, there is a point at which the scale could tip and $\phi$-ing becomes permissible (or even required). Now, it is clear that, if epistemic objectivism is true, independent evidence for $p$ fails this test. If believing $p$ is impermissible, this means that $p$ is false. And so there will not conceivably be a point at which enough independent evidence is added to make the belief that $p$ permissible (or even required). This confirms the intuitive verdict that, if objectivism is true, independent evidence cannot be a reason, precisely because it does not make any difference to all-things-considered facts about what one is permitted to believe.

The second constraint is: 
Weighing Constraint: If $R$ is a reason for or against $\phi$-ing, then there is a conceivable situation where it makes sense to weigh up $R$ and other reasons in deliberation about whether to $\phi$.

Weighing up reasons is what we do whenever we work ourselves toward an "ought" conclusion on the basis of competing contributory considerations. The above constraint expresses the plausible thought that, for something to be a reason, it must at least conceivably be the kind of thing that could play the contributory role in such reasoning.

Yet, Weighing Constraint rules out that both $p$ itself and independent evidence bearing on whether $p$ could be reasons for or against believing $p$. When making up one's mind about whether to believe $p$, it does not make sense, even conceivably, to entertain both $p$ and independent evidence bearing on whether $p$ in doxastic deliberation. All cases where $p$ 's truth is among the reasons that one weighs in deliberation are cases where the question of whether to believe $p$ is already settled in favor of believing it. If one of the considerations that one appeals to in doxastic deliberation is that $p$ is true, there is no point in weighing up $p$ 's truth against other reasons in order to find out whether $\mathrm{p}$ is true.

It is important to note that this constraint does not beg the question against objectivism. ${ }^{33}$ One might think that, in cases like Doctor, it would not make sense for Jill to weigh up the fact that pill $B$ is the cure against other reasons bearing on her decision. After all, Jill is not aware of this fact, and it might well seem that one could not sensibly appeal to facts in deliberation of which one is unaware. But since this fact is a reason according to objectivism, it would beg the question of whether Weighing Constraint ruled this out.

However, this is not what the constraint does. What it rules out is that something is a reason if there is no conceivable situation where it can sensibly be weighed up against other reasons. This is not true for the fact that $B$ is the cure, which one might sensibly weigh up against other reasons for or against prescribing it in all sorts of circumstances, even if in Jill's actual circumstances she could not sensibly appeal to this (unknown) fact. Still, with regard to $p$ 's truth in deliberation about whether $p$, this is not even conceivably the case. As Kiesewetter says in a related context, $p$ and independent evidence bearing on whether $p$

could not both be reasons in the same situation.... This is not because weighing them is practically impossible from your point of view, but because there is no single point of view from which these two facts can sensibly be weighed against each other. ${ }^{34}$ 
I conclude that, if epistemic objectivism is true, then only $p$-as opposed to independent evidence bearing on whether to believe $p$-is a reason to believe $p$.

\subsection{An Objection}

Before we embrace this conclusion, I want to consider the following objection: Impact Constraint and Weighing Constraint entail that only $p$ is a reason to believe $p$. But that contradicts a number of independently plausible views about the nature of reasons. For example, according to the Reasons-as-Evidence View, reasons to $\phi$ are evidence that one ought to $\phi .{ }^{35}$ On the Reasons-as-Explanations View, reasons to $\phi$ are considerations that explain why one ought to $\phi$. And on the Reasons-as-Premises View, reasons to $\phi$ are premises of good reasoning from these considerations toward $\phi$-ing. ${ }^{36}$ On all these views, independent evidence for $p$ is a reason to believe $p$. If the two constraints imply otherwise, then so much the worse for these constraints. ${ }^{37}$

Since it will be clear how my response generalizes to the other cases, I will make it explicit only for the case of the Reasons-as-Evidence View. The challenge is this: if the Reasons-as-Evidence View is correct, then independent evidence for $p$ indicates that $p$ is true, and so that one ought to believe $p$, and so, via the proposed analysis, that it is a reason to believe $p$. Since the two constraints deny this, they are inconsistent with an attractive view about the nature of reasons and so cannot support an argument against objectivism, at least without further defense.

The problem with this objection is that it begs the question against the proposed argument. There is a conflict between the two constraints and the independently plausible Reasons-as-Evidence View only if one already presupposes an objectivist reading of it. More precisely, the Reasons-as-Evidence View entails that both $p$ and independent evidence for $p$ are reasons to believe $p$ only if we already

point is not that it is conceptually impossible to weigh up $p$ and independent evidence bearing on $p$. One might think this to be the case, since weighing up $p$ in doxastic deliberation could seem to imply that one already believes $p$, so that all cases where one weighs up $p$ in deliberation are cases where one does not deliberate about whether to believe $p$ (since, in these cases, one has already answered this deliberative question). But one can also weigh up considerations in deliberation that one only supposes to be true. In these cases, appealing to a consideration does not imply already believing it, and so it seems conceptually possible to weigh it up against other reasons. But there is still no deliberative context where this would be coherent.

E.g., Kearns and Star, "Reasons as Evidence."

E.g., Broome, "Reasons"; Way, "Reasons as Premises of Good Reasoning."

Thanks to Benjamin Kiesewetter and an anonymous referee for pressing me on this point. 
agree that one must not impose any epistemic constraints on which facts can count as reasons for belief.

Consider, for example, a perspectivist version of this view, which says that for $R$ to be a reason to believe $p$ is for $R$ to be evidence that one ought to believe $p$, of the kind that could rationally figure in the agent's deliberation given her evidence. Since, at the time of deliberating about whether to believe $p, p$ could not rationally figure in such deliberation - at that point, whether $p$ is precisely what one is about to find out-it follows from a perspectivist construal of the Reasons-as-Evidence View that only independent evidence is a reason to believe $p$. So understood, there is no conflict with the two constraints, which rule out only that both $p$ and independent evidence for $p$ are reasons to believe $p$. The conflict arises only if we start with an objectivist construal of the Reasons-as-Evidence View, which imposes no restriction whatsoever on which pieces of evidence can be reasons for belief. Yet in assessing these constraints, we cannot just presuppose an objectivist construal of the Reasons-as-Evidence View, since whether that view should be understood in an objectivist way or not is the very question currently at issue.

To put the same point differently: endorsing the two constraints does not contradict the Reasons-as-Evidence View, as long as one does not build an objectivist reading right into it. If one is sympathetic to the Reasons-as-Evidence View, the fact that an objectivist version of it would conflict with two independently plausible constraints about reasons is thus, if anything, a reason against endorsing an objectivist version of this view. The proposed conflict is illusory, unless we already assume that the only way for the Reasons-as-Evidence View to be true is for an objectivist version of it to be true, in which case we are begging the question against perspectivism. While I lack the space to go through this line of response for the other cases, it should be clear that the strategy generalizes. In all these cases, the proposed views conflict with the two constraints only if one already assumes that the right way to understand these views is along objectivist lines.

We should conclude that, given two independently plausible constraints about reasons, which are also compatible with a number of plausible views about the nature of reasons, objectivism implies that only $p$ is a reason to believe $p$. This does not mean, of course, that objectivists must deny that independent evidence for $p$ can play other normatively significant roles. For example, such evidence might explain why people are sometimes not blameworthy for their false beliefs. Still, objectivists have to deny that such evidence is ever a normative reason to believe something. 


\subsection{How Objectivism Makes Correct Guidance Impossible}

The first premise of the Infection Argument says that epistemic objectivism rules out the possibility of believing normative propositions for the right reasons. As we have seen, if epistemic objectivism is true, then the only reason to believe $p$, and in fact the only right reason to believe $p$, is that $p$ is true. Epistemic objectivism asserts this for all propositions. But, as I will now argue, the truth of a normative proposition (as opposed to independent evidence for it) is not a reason for which one could possibly believe that proposition.

There are several arguments for this claim. First of all, it is supported by widespread assumptions in the extant literature on the epistemic basing relation. For example, Ian Evans seems to assume that there is in fact no proposition, let alone a normative proposition, that could be believed on the basis of its own truth:

Very many of our beliefs are based on other beliefs. Some are based on perceptual experiences and some are based on apparent memories. Others are based on desires, fears, vanity, prejudices and other epistemically disreputable states. Perhaps some of our beliefs are baseless... A pervasive thought is that for a belief to be justified by some evidence, it is at least necessary that it be based on that evidence. ${ }^{38}$

Evans here lists a number of candidate examples for the kinds of things that a belief could be based on. What we do not find among his suggestions is the truth of the proposition believed. Similarly, Allen Korcz's Stanford Encyclopedia entry on epistemic basing never explicitly mentions the possibility that $p$ 's truth can be the reason for which someone believes that $p$; the same goes for Kurt Sylvan's survey article. ${ }^{39}$

Furthermore, there are influential theories of the epistemic basing relation that directly contradict this possibility. For example, Paul Moser's causal theory assumes the following necessary condition: ${ }^{40}$

Moser's Condition: A belief that $p$ is based on $q$ only if the belief that $p$ is

(non-deviantly) causally sustained by the belief that $q$.

According to this condition, a belief that $p$ would be based on $p$ itself only if the belief that $p$ causally sustained itself. But unlike God, perhaps, a belief is not a causally self-sustaining entity. It thus follows from the condition that a belief that $p$ is not possibly based on $p$ itself.

38 Evans, "The Problem of the Basing Relation," 2943.

39 Korcz, "The Epistemic Basing Relation”; Sylvan, "Epistemic Reasons II."

40 Moser, Knowledge and Evidence. 
Similarly, Evans's dispositional theory explicitly assumes that "beliefs can only be based on other mental states." ${ }^{41}$ This immediately entails that one cannot believe $p$ on the basis of $p$ 's truth, since $p$ 's truth is not a mental state. In general, it seems that only certain doxastic theories, according to which $S$ 's belief that $p$ is based on $q$ if and only if $S$ has an appropriate meta-belief that $q$ is a good reason to believe $p$, are at least compatible with the possibility of believing $p$ for the reason that $p .^{42}$ But doxastic theories are controversial, and not all versions of such a view are consistent with this possibility. ${ }^{43}$

The extant literature on epistemic basing hence does not leave much room for the claim that the epistemic objectivist's reasons to believe normative propositions are reasons for which people could believe such propositions. Since a detailed discussion of this literature is beyond the scope of this paper, I will not go into further details here. Instead, I will offer three independent reasons for thinking that it is impossible to believe a proposition for what is, according to objectivism, the only right reason to believe it.

First, consider considerations of theoretical simplicity. Everyone, even epistemic objectivists, must accept that at least some normative beliefs are based on independent evidence for these beliefs. For example, you could believe that $p$ while having forgotten the reason for which you believe $p$. But then the reason for which you believe that $p$ cannot be that $p$, since you cannot at the same time believe that $p$ and have forgotten that $p$. Alternatively, consider false beliefs. Your false belief that killing other people for fun is morally permissible cannot be held for the reason that killing other people for fun is morally permissible, since killing other people for fun is not morally permissible. But if some truth-related normative beliefs are based on independent evidence, it is just more economical to assume that this is true for all such beliefs, rather than assuming that some normative beliefs are based on their truth whereas others are based on independent evidence for their truth. ${ }^{44}$

Second, assuming that one could believe a normative proposition for the reason that it is true commits objectivists to a very strong form of intuitionism, according to which we can stand in a relation of direct acquaintance to norma-

Evans, “The Problem of the Basing Relation," 2945.

See, e.g., Tolliver, "Basing Beliefs on Reasons."

Some versions of the doxastic view deny that appropriate meta-beliefs are sufficient for a basing relation to obtain. Since these versions include additional causal conditions, they rule out that a belief that $p$ could be based on $p$ for the reason given above. Cf. Korcz, "The Epistemic Basing Relation," sec. 3.

By "truth-related" beliefs I mean beliefs that are not held for pragmatic reasons. I leave it open whether there are any beliefs that are not truth related in this sense. 
tive facts. It should be clear that this is a very strong commitment, which invites all the problems that come with this sort of intuitionist normative epistemology. To be sure, such an epistemology might be quite plausible with respect to some classes of propositions, such as phenomenal propositions like "I have a pleasurable experience right now." Perhaps we can be directly acquainted with such truths; after all, it seeming to me that I have a pleasurable experience just is for me to have such an experience. So perhaps I cannot be mistaken about my having it, in which case it might seem plausible to say that I am directly acquainted with the fact of my having it or, in other words, that my believing to have this experience is based on my really having the experience.

But the case of normative truths is very different. In the normative case, it seeming to me that $p$ does not make it the case that $p$, since my belief might be mistaken despite the seeming. So the reason for thinking that I am directly acquainted with $p$ that applied in the phenomenal case does not apply here. This makes it all the more doubtful that normative propositions are among the propositions that could be believed on the basis of their truth. In general, it would clearly be better for a view about the perspective dependence of "ought" not to commit one to such controversial claims in normative epistemology.

Third, consider the psychology of false belief. To ask whether believers can acquire or maintain a belief on the basis of its truth is to ask whether truth is a reason for which one could believe. To ask whether something is a reason for which one could believe is to ask a question about psychology. Note, however, that the psychology of acquiring or maintaining false normative beliefs does not seem to differ in kind from the psychology of acquiring or maintaining true normative beliefs. My belief that $p$ when $p$ is true does not seem to differ psychologically, just because it is true, from my belief that $p$ when $p$ is false.

To illustrate, let us say you believe that killing other people for fun is morally impermissible. Now suppose that I, unlike you, got things horribly wrong about morality, believing that killing other people for fun is morally permissible. I might believe this because an ill-meaning authority told me so, or because I have been brainwashed. But it is certainly possible that no such thing occurred, and that I hold my belief because it seems as self-evidently true to me as your belief seems to you. In such a case, the psychological processes that led me to forming my false belief seem to be of the same kind as the psychological processes that led you to forming your true belief. Since the reason for which someone holds a belief is a matter of the psychological processes that led her to forming it, the reason for which I hold my belief thus seems to be of the same kind as the reason for which you hold your belief. Since my belief is actually false and so the reason for which I hold it cannot be that it is actually true, the same must then be 
true for your belief. Instead, both beliefs are held for the reason that they seem self-evident to the person holding the belief. It is just that what is self-evident to one person need not be self-evident to another, and in this case, I was unlucky enough for an appearance of self-evidence to lead me astray.

In general, false normative beliefs are acquired and maintained for all sorts of reasons, including various types of evidence, superstition, habit, prejudice, or self-deception. There is just one reason for which a false normative belief cannot be held: its actually being true. But if a false normative proposition cannot be believed for the reason that it is true, and if the psychology of acquiring or maintaining true normative beliefs does not differ in kind from the psychology of acquiring or maintaining false normative beliefs, then it seems that a true normative proposition cannot be believed for the reason that it is true, either. True normative beliefs must instead be acquired or maintained for those other kinds of reasons, such as independent evidence.

What does this mean for the Infection Argument? We have seen that, if epistemic objectivism is true, only the truth of $p$ is a reason to believe $p$. But as the above arguments show, $p$ 's truth—for some normative proposition $p$-is not a reason for which one could believe $p$. Hence, epistemic objectivism rules out that people ever believe normative propositions for the reason which, according to objectivism, is the right reason to believe such a proposition, viz., that it is true.

Now recall condition $\mathrm{B} 2$ in my earlier analysis of correct action guidance. For correct action guidance to be possible, it must be possible for an agent to perform the action required by a theory on the basis of correct practical reasoning from that theory. This, in turn, requires not just that the agent believes, for some $R$ that decisively favors the action according to the theory, that $R$ decisively favors the theory, but also that she believes this for the right reason.

However, that is precisely what is ruled out by objectivism. To return to our earlier example, if objectivism holds in both the practical and the epistemic domain, then the right reason to believe that promises generate decisive reasons according to Kantianism-now assuming an objectivist version of Kantianism-is that the categorical imperative actually entails this. In other words, it is the truth of the proposition "the categorical imperative entails such-and-such" that is the right reason to believe this proposition and not, as in a perspectivist version of Kantianism, that the available evidence suggests that the categorical imperative entails this.

As we have seen, however, the fact that the categorical imperative actually entails $X$ is not a reason for which one could believe that it entails $X$. If an objectivist version of Kantianism is true, the only right reason to believe that promises 
generate decisive reasons is hence a reason for which it is impossible to believe that promises generate decisive reasons. If epistemic objectivism is true, it is thus impossible for $\mathrm{B} 2$ to be satisfied, and so impossible to act on the basis of correct practical reasoning from Kantianism toward the action required by Kantianism. Ultimately, if objectivism is true, it is impossible to be correctly guided by that theory (mutatis mutandis for normative theories other than Kantianism).

Perspectivism, on the other hand, avoids this result: that there is sufficient evidence for the proposition "the categorical imperative entails such-and-such" is a right reason to believe that proposition according to perspectivism, and it is also a reason for which one could believe that proposition.

I conclude that, if objectivism is true, then it is impossible to believe a normative proposition for the right reason. This establishes premise 1 of the Infection Argument, which in turn establishes the crucial premise of the Argument from Action Guidance: that, if objectivism is true, it is impossible for someone's action to be correctly guided by a normative theory. Since that is implausible, so is objectivism.

\section{CONCLUSION}

In this essay, I have provided a new guidance-based argument against objectivism about the practical "ought." This argument draws together two separate themes from the recent literature: first, that the normative is in some sense action guiding, and second, that the parallel between practical and epistemic normativity provides fruitful resources for debating the plausibility of objectivism and competing views.

The main idea behind the argument was to show that if objectivism is true then, implausibly, it is impossible for an action to be correctly guided by a normative theory. In defense of this argument, I developed a substantive account of what it is for a normative theory to correctly guide action. The crucial condition of this analysis says that correct guidance requires the capacity to believe normative propositions for the right reasons. But since practical objectivism entails epistemic objectivism, and epistemic objectivism rules out this capacity, it follows that correct guidance is impossible.

Not only is this an unacceptable result, it is also a result that perspectivism easily avoids. This provides a robust, theory-driven argument against objectivism, which does not just appeal to contested intuitions about particular cases but 
also sheds light on a notion of action guidance that should be of independent interest to normative theory. ${ }^{45}$

\section{REFERENCES}

Andrić, Vuko. "The Case of the Miners." Journal of Ethics and Social Philosophy 7 , no. 1 (January 2013): 1-8.

. "Objective Consequentialism and the Licensing Dilemma." Philosophical Studies 162, no. 3 (February 2013): 547-66.

- "Objective Consequentialism and the Rationales of 'Ought' Implies 'Can.'” Ratio 30, no. 1 (March 2017): 72-87.

Björnsson, Gunnar, and Stephen Finlay. "Metaethical Contextualism Defended." Ethics 121, no. 1 (October 2010): 7-36.

Boghossian, Paul. "Is Meaning Normative?" In Content and Justification: Philosophical Papers, 95-108. Oxford: Oxford University Press, 2008.

Broome, John. Rationality through Reasoning. Oxford: Wiley Blackwell, 2013.

. "Reasons." In Reason and Value: Themes from the Moral Philosophy of Joseph Raz, edited by Jay Wallace, Michael Smith, Samuel Scheffler, and Philip Pettit, 28-55. Oxford: Oxford University Press, 2004.

Bykvist, Krister. "How to Do Wrong Knowingly and Get Away with It." In Neither/Nor: Philosophical Papers Dedicated to Erik Carlson on the Occasion of His Fiftieth Birthday, edited by Rysiek Sliwinski and Frans Svensson, 31-47. Uppsala, Sweden: Uppsala Philosophical Studies, 2011.

Evans, Ian. "The Problem of the Basing Relation." Synthese 190, no. 14 (September 2013): $2943-57$.

Gibbard, Allan. "Truth and Correct Belief." Philosophical Issues 15 (2005): 338-50. Gibbons, John. The Norm of Belief. Oxford: Oxford University Press, 2013.

45 For their helpful comments on earlier versions of this article, I would like to thank Daniele Bruno, Jonas Burgstahler, Jan Grohn, Marcel Jahn, Benjamin Kiesewetter, Thomas Schmidt, Jonathan Way, the participants of Thomas Schmidt's ethics colloquium, and the editor of this journal, Mark Schroeder, along with two anonymous referees. I would also like to thank the participants of a graduate seminar on ignorance and moral responsibility by Thomas Schmidt and Daniele Bruno at Humboldt University, Berlin, for their comments on some of the previous material that made it into this article. Work on this project has been supported by the Studienstiftung des deutschen Volkes. 
Graham, Peter A. "In Defense of Objectivism about Moral Obligation." Ethics 121, no. 1 (October 2010): 88-115.

Henning, Tim. "Normative Reasons Contextualism." Philosophy and Phenomenological Research 88, no. 3 (May 2014): 593-624.

Hills, Alison. "What Does It Take to Act for Moral Reasons?" In The Many Moral Rationalisms, edited by Karen Jones and François Schroeter, 247-63. Oxford: Oxford University Press, 2018.

Jackson, Frank. "Decision-Theoretic Consequentialism and the Nearest and Dearest Objection." Ethics 101, no. 3 (April 1991): 461-82.

Kearns, Stephen, and Daniel Star. "Reasons as Evidence." Oxford Studies in Metaethics, vol. 4, edited by Russ Shafer-Landau, 215-42. Oxford: Oxford University Press, 2009.

Kiesewetter, Benjamin. "How Reasons Are Sensitive to Available Evidence." In Normativity: Epistemic and Practical, edited by Conor McHugh, Jonathan Way, and Daniel Whiting, 90-114. Oxford: Oxford University Press, 2018.

- The Normativity of Rationality. Oxford University Press, Oxford, 2018. . "'Ought' and the Perspective of the Agent." Journal of Ethics and Social Philosophy 5, no. 3 (October 2011): 1-24.

- "What Kind of Perspectivism?" Journal of Moral Philosophy 15, no. 4 (2018): 415-43.

Kolodny, Niko. "How Does Coherence Matter?" Proceedings of the Aristotelian Society 107, no. 3 (October 2007): 229-63.

Kolodny, Niko, and John MacFarlane. "Ifs and Oughts." Journal of Philosophy 107, no. 3 (March 2010): 115-43.

Korcz, Keith Allen. "The Epistemic Basing Relation." Stanford Encyclopedia of Philosophy (Fall 2015). https://plato.stanford.edu/archives/fall2015/entries/ basing-epistemic.

Littlejohn, Clayton. "Do Reasons and Evidence Share the Same Residence?" Unpublished manuscript.

- Justification and the Truth-Connection. Cambridge: Cambridge University Press, 2012.

—. "Prichard's Question and Reasons Perspectivism." Unpublished manuscript.

. "The Unity of Reason." In Epistemic Norms: New Essays on Action, Belief, and Assertion, edited by Clayton Littlejohn and John Turri, 135-54. Oxford: Oxford University Press, 2014.

Lord, Errol. "Acting for the Right Reasons, Abilities, and Obligation." In Oxford Studies in Metaethics, vol. 10, edited by Russ Shafer-Landau, 26-52. Oxford: Oxford University Press, 2015. 
- "The Real Symmetry Problem(s) for Wide-Scope Accounts of Rationality." Philosophical Studies 170, no. 3 (September 2014): 443-64.

$\mathrm{McHugh}$, Conor, and Jonathan Way. "Objectivism and Perspectivism about the Epistemic Ought.” Ergo 4, no. 5 (2017): 121-45.

Moore, G. E. Ethics. New York: H. Holt and Co., 1912.

Moser, Paul K. Knowledge and Evidence. Cambridge University Press, Cambridge, 1989.

Piller, Christian. "Ewing's Problem." European Journal of Analytic Philosophy 3, no. 1 (2007): 43-65.

Pittard, John, and Alex Worsnip. "Metanormative Contextualism and Normative Uncertainty." Mind 126, no. 501 (January 2017): 155-93.

Prichard, H. A. "Duty and Ignorance of Fact." In Moral Writings, 84-101. Oxford: Clarendon Press, 2002.

Robertson, Simon. "Epistemic Constraints on Practical Normativity." Synthese 181, supplement 1 (August 2011): 81-106.

Ross, W.D. The Right and the Good. Oxford: Clarendon Press, 1930.

Scanlon, Thomas. What We Owe to Each Other. Cambridge, MA: Belknap Press of Harvard University Press, 1998.

Schroeder, Mark. "Knowledge Is Belief for Sufficient (Objective and Subjective) Reasons." In Oxford Studies in Epistemology, vol. 5, edited by Tamar S. Gendler and John Hawthorne, 226-52. Oxford: Oxford University Press, 2015.

- . "Getting Perspective on Objective Reasons." Ethics 128, no. 2 (January 2018): 289-319.

Sepielli, Andrew. "Subjective Normativity and Action-Guidance." Oxford Studies in Normative Ethics, vol. 2, edited by Mark Timmons, 45-73. Oxford: Oxford University Press, 2012.

Shah, Nishi. "How Truth Governs Belief." Philosophical Review 112, no. 4 (October 2003): 447-82.

Shah, Nishi, and J. David Velleman. "Doxastic Deliberation." Philosophical Review 114, no. 4 (October 2005): 497-534.

Sylvan, Kurt. "Epistemic Reasons II: Basing." Philosophy Compass 11, no. 7 (July 2016): 377-89.

Thomson, Judith Jarvis. “Imposing Risks." In Rights, Restitution, and Risk, 173-91. Cambridge, MA: Harvard University Press, 1986.

- Normativity. Chicago: Open Court, 2008.

Tolliver, Joseph. "Basing Beliefs on Reasons." Grazer Philosophische Studien 15, no. 1 (1982): 149-61.

Way, Jonathan. "Reasons as Premises of Good Reasoning." Pacific Philosophical Quarterly 98, no.2 (June 2017): 251-70. 
."The Symmetry of Rational Requirements." Philosophical Studies 155, no. 2 (September 2011): 227-39.

Way, Jonathan, and Daniel Whiting. "Perspectivism and the Argument from Guidance." Ethical Theory and Moral Practice 20, no. 2 (April 2017): 361-74. Wedgwood, Ralph. "The Aim of Belief." Philosophical Perspectives 16 (2002): 267-97.

Weiner, Matthew. “The Spectra of Epistemic Norms." In Epistemic Norms: New Essays on Action, Belief, and Assertion, edited by Clayton Littlejohn and John Turri, 201-18. Oxford: Oxford University Press, 2014.

Whiting, Daniel. “Should I Believe the Truth?” Dialectica 64, no. 2 (June 2010): 213-24.

Zimmermann, Michael J. Ignorance and Moral Obligation. Oxford: Oxford University Press, 2014.

- Living with Uncertainty: The Moral Significance of Ignorance, Cambridge: Cambridge University Press, 2008. 